\title{
Systemic inflammatory response syndrome, infection, and outcome in intracerebral hemorrhage
}

\section{OPEN}

Amelia K. Boehme, PhD, MSPH

Mary E. Comeau, MS

Carl D. Langefeld, PhD

Aaron Lord, MD

Charles J. Moomaw, PhD

Jennifer Osborne, RN, BSN

Michael L. James, MD

Sharyl Martini, MD, PhD

Fernando D. Testai, MD, $\mathrm{PhD}$

Daniel Woo, MD, MS

Mitchell S.V. Elkind, MD, MS

Correspondence to

Dr. Boehme:

akb2188@columbia.ed

Supplemental data at Neurology.org/nn

\section{ABSTRACT}

Objective: Systemic inflammatory response syndrome (SIRS) may be related to poor outcomes after intracerebral hemorrhage (ICH).

Methods: The Ethnic/Racial Variations of Intracerebral Hemorrhage study is an observational study of $\mathrm{ICH}$ in whites, blacks, and Hispanics throughout the United Sates. SIRS was defined by standard criteria as 2 or more of the following on admission: (1) body temperature $<36^{\circ} \mathrm{C}$ or $>38^{\circ} \mathrm{C}$, (2) heart rate $>90$ beats per minute, (3) respiratory rate $>20$ breaths per minute, or (4) white blood cell count $<4,000 / \mathrm{mm}^{3}$ or $>12,000 / \mathrm{mm}^{3}$. The relationship among SIRS, infection, and poor outcome (modified Rankin Scale [mRS] 3-6) at discharge and 3 months was assessed.

Results: Of 2,441 patients included, 343 (14\%) met SIRS criteria at admission. Patients with SIRS were younger (58.2 vs 62.7 years; $p<0.0001$ ) and more likely to have intraventricular hemorrhage (IVH; 53.6\% vs 36.7\%; $p<0.0001)$, higher admission hematoma volume (25.4 vs $17.5 \mathrm{~mL} ; p<0.0001$ ), and lower admission Glasgow Coma Scale (GCS; 10.7 vs 13.1; $p<$ 0.0001). SIRS on admission was significantly related to infections during hospitalization (adjusted odds ratio [OR] 1.36, 95\% confidence interval [CI] 1.04-1.78). In unadjusted analyses, SIRS was associated with poor outcomes at discharge (OR 1.96, 95\% Cl 1.42-2.70) and 3 months (OR 1.75, 95\% Cl 1.35-2.33) after ICH. In analyses adjusted for infection, age, IVH, hematoma location, admission GCS, and premorbid mRS, SIRS was no longer associated with poor outcomes.

Conclusions: SIRS on admission is associated with $\mathrm{ICH}$ score on admission and infection, but it was not an independent predictor of poor functional outcomes after $\mathrm{ICH}$. Neurol Neuroimmunol Neuroinflamm 2018;5:e428; doi: 10.1212/NXI.0000000000000428

\section{GLOSSARY}

$\mathbf{C I}=$ confidence interval; $\mathbf{C R P}=$ C-reactive protein; ERICH = Ethnic/Racial Variations of Intracerebral Hemorrhage; $\mathbf{I C H}=$ intracerebral hemorrhage; IVH = intraventricular hemorrhage; $\mathbf{m R S}=$ modified Rankin Scale; OR = odds ratio; SIRS = systemic inflammatory response syndrome.

Prevention and management of complications after stroke is an integral component of stroke treatment. ${ }^{1}$ Infectious complications after intracerebral hemorrhage $(\mathrm{ICH})$ have been identified as a marker of poor clinical condition, and as such are believed to be a significant contributor to post-ICH death and disability. ${ }^{2}$ In addition to infections, inflammatory responses have been associated with poor poststroke outcomes. One such inflammatory response, systemic inflammatory response syndrome (SIRS), is characterized by the presence of 2 or more of the following: hyperthermia or hypothermia, leukopenia or leukocytosis, tachycardia, or tachypnea and is believed to be a systemic reaction to a stimulus (e.g., trauma and surgery). ${ }^{3}$ SIRS has been recognized in nonneurologic illnesses, as well as in ischemic stroke, and patients with

\footnotetext{
From the Department of Neurology (A.K.B., M.S.V.E.), College of Physicians and Surgeons, Columbia University; Department of Epidemiology (A.K.B., M.S.V.E.), Mailman School of Public Health, Columbia University, New York, NY; Wake Forest University (M.E.C., C.D.L.), NC; Department of Neurology (A.L.), New York University School of Medicine; Department of Neurology and Rehabilitation Medicine (C.J.M., J.O., D.W.), University of Cincinnati, OH; Departments of Anesthesiology and Neurology (M.L.J.), Duke University, Durham, NC; Baylor University, Houston, TX (S.M.); and University of Illinois Chicago (F.D.T.).

Funding information and disclosures are provided at the end of the article. Go to Neurology.org/nn for full disclosure forms. The Article Processing Charge was funded by the authors.

This is an open access article distributed under the terms of the Creative Commons Attribution-NonCommercial-NoDerivatives License 4.0 (CC BY-NC-ND), which permits downloading and sharing the work provided it is properly cited. The work cannot be changed in any way or used commercially without permission from the journal.
} 
subarachnoid hemorrhage as a risk factor for poor outcomes. ${ }^{4-6}$ In addition, a relationship between SIRS and stroke severity has been identified in patients with ICH and subarachnoid hemorrhage, ${ }^{6}$ as well as with stroke severity and infarct volume in patients with ischemic stroke. ${ }^{7}$ Although prior work has demonstrated a relationship between SIRS and functional outcomes, independent of infection, only 1 single-center study has investigated the role of SIRS on the ICH outcome in the absence of an infection. ${ }^{8}$ SIRS on admission has also been associated with persistent SIRS during an ICH hospitalization in a single-center study, but no study has yet assessed the effect of SIRS identified at the time of admission on stroke outcomes at discharge or later in patients with ICH. The presence of SIRS in patients with ICH at hospital admission was hypothesized to be related to increased risk of poor outcomes at discharge and 3 months.

METHODS The Ethnic/Racial Variations of Intracerebral Hemorrhage (ERICH) study is a prospective, multicenter study of ICH among white, black, and Hispanic patients. The ERICH study comprised 19 recruitment centers throughout the United States, and the methods have been published previously. ${ }^{2}$ Recruitment periods varied by recruitment center, with enrollment ranging from September 2010 through October 2015. Patients were enrolled in the study if they had spontaneous $\mathrm{ICH}$, were $\geq 18$ years of age, lived within 75 miles of one of the recruitment centers, identified as non-Hispanic white, nonHispanic black, or Hispanic, and provided informed consent, either through their own volition or through a legal representative.

$\mathrm{ICH}$ was defined as a nontraumatic, spontaneous focal blood collection within the brain parenchyma (including peripartum and anticoagulation-associated ICH) seen on neuroimaging with an abrupt onset of severe headache, altered level of consciousness, or focal neurologic deficit. ${ }^{9,10}$ Cases of $\mathrm{ICH}$ due to hemorrhagic conversion of a recent ischemic stroke, malignancy-associated coagulopathy, dural venous sinus thrombosis, vascular malformations, aneurysms, or tumors were excluded. Patients were excluded from the present analysis if they died within 72 hours of admission, if they were missing information preventing the assessment of SIRS on admission, and if there was no information on the discharge outcome. A sensitivity analysis was conducted including the patients who died within 72 hours of admission.

Standard protocol approvals, registrations, and patient consents. The study was approved by the institutional review boards at the participating centers. Eligible participants were approached for informed consent to participate in this study.

Data collection and variable definition. Demographic and clinical data collected on the case report forms at each center included medical history, imaging, and laboratory data. The central imaging core determined the ICH location and volume, as well as the presence of intraventricular hemorrhage (IVH). ICH locations were categorized as brainstem, cerebellum, deep, lobar, and primary IVH. In the adjusted analyses, the ICH location was recategorized as lobar vs. all others (brainstem, cerebellum, deep, and primary IVH). ICH scores were calculated for each patient as a measure of stroke severity, with points assigned for age 80 or older, Glasgow Coma Scale (GCS) at presentation, ICH volume greater than $30 \mathrm{~mL}$, presence of IVH, and infratentorial origin of hemorrhage. ${ }^{9}$ In adjusted models, the location was divided into lobar vs nonlobar.

The presence of SIRS was defined as having 2 or more of the following (per standard criteria): (1) heart rate greater than 90 beats per minute, (2) respiratory rate greater than 20 breaths per minute, (3) white blood cell count less than $4,000 / \mathrm{mm}^{3}$ or greater than $12,000 / \mathrm{mm}^{3}$ or more than $10 \%$ of polymorphonuclear leukocytes, or (4) body temperature less than $36^{\circ} \mathrm{C}$ or greater than $38^{\circ} \mathrm{C} ., 10$ For the present analysis, the SIRS status was based on vital sign and laboratory data at the time of hospital admission for ICH. Case report forms did not record vital sign and laboratory information after admission; therefore, SIRS that may have developed during the hospital stay could not be determined. SIRS was considered present if 2 or more of the necessary criteria were met on admission. This was a more transient definition without a strict timeframe criterion that has been used in prior research. In-hospital treatments and infections were documented. Infections were identified throughout the entire hospital stay from the medical records, and they were reported on the chart abstraction form. Infections were defined as a diagnosis of infection any time during the hospital stay that was noted in the medical record with categories including respiratory, urinary, bloodstream, ventriculitis, and other.

The primary outcome was poor functional outcome at discharge and 3 months, defined as a modified Rankin Scale (mRS) score of 3-6. ${ }^{11}$

Statistical analyses. The $\chi^{2}$ test of independence was used to assess baseline demographic differences between patients with SIRS and those without SIRS for categorical variables, and the Wilcoxon rank sum test was used for continuous variables. Odds ratios (ORs) and 95\% confidence intervals (CIs) (OR, 95\% CI) were calculated for crude and adjusted logistic regression models to estimate the odds of poor outcomes for patients with SIRS. No adjustments were made for multiple comparisons, as this was an exploratory analysis. ${ }^{12}$ Additional analyses were conducted to assess the relationship among infection, SIRS, and SIRS plus infection on the outcomes of interest and to explore the associations in those with less severe strokes and premorbid disability. An alpha of 0.05 was set as the level of significance.

RESULTS Of 2,997 ICH cases enrolled in the ERICH study before November 2015, 472 were excluded for unknown SIRS criteria because of missing data; 76 were excluded because of death within 72 hours of admission; and 8 were excluded for missing discharge outcome data, leaving 2,441 available for analysis. The majority of the patients with $\mathrm{ICH}$ were admitted within 24 hours of symptom onset (86.4\%), with $8.4 \%$ of the patients with ICH admitted between 24 and 72 hours, and $5.2 \%$ of the patients admitted within 72 hours of symptom onset. Of the patients who met inclusion criteria, 343 (14.1\%) met SIRS criteria on admission, of which $300(87.5 \%)$ met only 2 criteria, $40(11.7 \%)$ met 3 


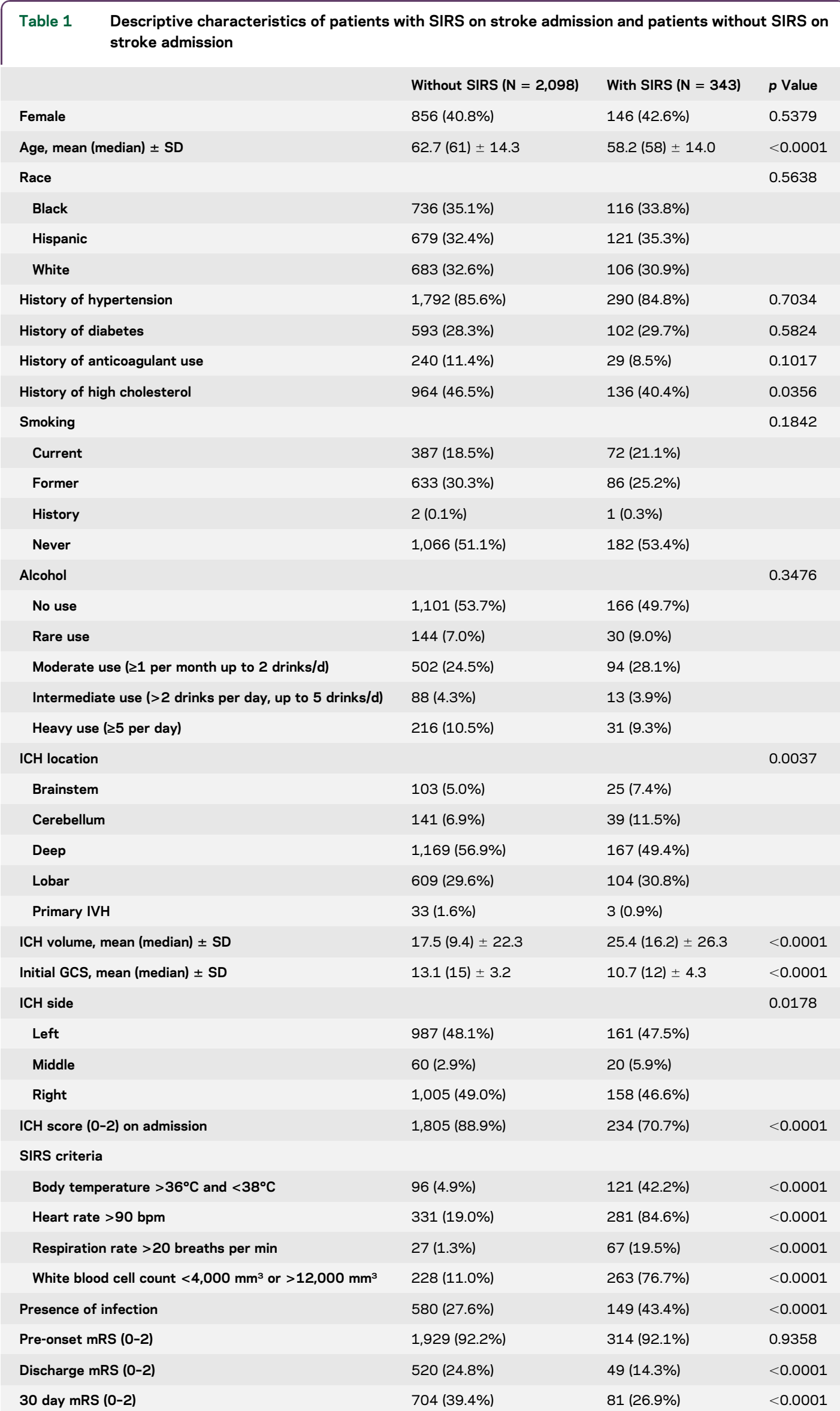

Abbreviations: ICH = intracerebral hemorrhage; IVH = intraventricular hemorrhage; $\mathrm{mRS}=$ modified Rankin Scale; SIRS = systemic inflammatory response syndrome. 
SIRS criteria, and $3(0.9 \%)$ met all 4 SIRS criteria. Patients with ICH who had SIRS on admission were younger (58.2 vs 62.7 years; $p<0.0001$ ), had a higher initial ICH volume (25.4 vs $17.5 \mathrm{~mL} ; p<$ $0.0001)$, had a lower GCS score on admission (10.7 vs $13.1 ; p<0.0001$ ), and different distributions in the hematoma location (table 1).

Patients with SIRS on admission were at increased risk of infections identified during the hospital stay than patients without SIRS on admission (OR 2.01, 95\% CI 1.59-2.54, $p<0.0001)$. SIRS on admission remained a significant risk factor for infection during ICH admission after adjusting for race/ ethnicity, hematoma volume and location, intubation, extraventricular drain (EVD) placement, dysphagia, percutaneous endoscopic gastrostomy (PEG) tube placement, and deep vein thrombosis (DVT) (OR 1.36, 95\% CI 1.04-1.78, $p=0.0258$ ). Restricting the analysis to patients who presented with an ICH score of 0-2 patients with SIRS on admission remained at increased risk of an infection during their ICH stay after adjusting for race/ethnicity, hematoma volume and location, intubation, EVD placement, dysphagia, PEG tube placement, and DVT (OR 1.54, 95\% CI 1.12-2.11, $p=0.0079)$.

Patients with SIRS on admission were at increased risk of poor outcomes at both discharge (OR 1.96, 95\% CI 1.42-2.70, $p<0.0001)$ and 3 months (OR 1.75, 95\% CI 1.35-2.33, $p<0.0001$ ). After adjusting for age, infections, IVH, hematoma volume and location, initial GCS, and preonset mRS, however, SIRS at admission no longer independently predicted outcomes (table 2). The relationship between SIRS and outcomes was primarily attenuated by adjustment for initial hematoma volume, GCS on admission, and presence of IVH. We conducted a stratified analysis in patients who had an $\mathrm{ICH}$ score of 0-2 on admission because of the extremely strong relationship between ICH score and outcomes. Similar to the entire sample, in the unadjusted analyses, SIRS on admission was related to poor functional outcomes at discharge (OR 1.61, 95\% CI 1.142.28, $p=0.0067$ ) and 3 months (OR 1.45, 95\% CI 1.07-1.96, $p=0.0196$ ), but this relationship did not persist after adjusting for age, infections, IVH, hematoma volume, hematoma location, initial GCS, and preonset mRS (table 2).

An additional analysis limiting the sample to only patients who had a pre-ICH mRS of 0-2 was conducted because of concerns surrounding the relationship between pre-ICH morbidity and subsequent outcomes. SIRS on admission was related to both discharge (OR 2.00, 95\% CI 1.45-2.78, $p<$ 0.0001 ) and 3-month poor functional outcomes (OR 1.78, 95\% CI 1.35-2.32, $p<0.0001$ ) in the unadjusted analyses, but after adjusting for potential confounders, these relationships were no longer significant (table 2). In a sensitivity analysis that also included patients who died within 72 hours, the effect sizes did not change (table e-1 at Neurology.org/nn).

We further classified patients as (1) SIRS with infection, (2) SIRS only, (3) infection only, and (3) neither SIRS nor infection to assess the relationship between these categories and functional outcomes (table 3). Patients with both SIRS and infections (OR 4.55, 95\% CI 2.04-10.0, $p=0.0002$ ), as well as patients with only an infection (OR 3.45, 95\% CI $2.38-5.00, p<0.0001)$ were at increased risk of poor functional outcomes at discharge after ICH after adjusting for age, IVH, hematoma volume and location (lobar vs nonlobar), and initial GCS. Patients with SIRS only were not at increased risk of poor functional outcomes at discharge after ICH (OR 1.07, 95\% CI $0.69-1.67, p=0.7452$ ) after adjusting for

Table 2 SIRS on admission and odds of poor functional outcomes after ICH

\begin{tabular}{|c|c|c|c|c|c|c|}
\hline & \multicolumn{3}{|c|}{ Discharge mRS 3-6 } & \multicolumn{3}{|c|}{ 3-Mo mRS 3-6 } \\
\hline & OR & $95 \% \mathrm{Cl}$ & p Value & OR & $95 \% \mathrm{Cl}$ & p Value \\
\hline Adjusted SIRS ${ }^{a}$ & 1.30 & $0.88-1.92$ & 0.1835 & 1.23 & $0.88-1.72$ & 0.2326 \\
\hline Unadjusted SIRS & 1.61 & $1.14-2.28$ & 0.0067 & 1.45 & $1.07-1.96$ & 0.0196 \\
\hline Adjusted SIRS ${ }^{a}$ & 1.34 & $0.89-2.00$ & 0.1567 & 1.22 & $0.85-1.75$ & 0.2679 \\
\hline \multicolumn{7}{|c|}{ Limiting to patients who had a pre-ICH mRS of $0-2$} \\
\hline Unadjusted SIRS & 2.00 & $1.45-2.78$ & $<0.0001$ & 1.78 & $1.35-2.32$ & $<0.0001$ \\
\hline
\end{tabular}

Abbreviations: $\mathrm{Cl}=$ confidence interval; $\mathrm{ICH}=$ intracerebral hemorrhage; IVH = intraventricular hemorrhage; mRS = modified Rankin Scale; OR = odds ratio; SIRS = systemic inflammatory response syndrome.

a Adjusted for age, infections, IVH, ICH location, initial GCS, and preonset mRS.

${ }^{\mathrm{b}}$ Adjusted for age, infections, IVH, ICH location, and initial GCS. 


\begin{tabular}{|c|c|c|c|c|c|c|c|}
\hline \multirow[t]{3}{*}{ Table 3} & \multicolumn{7}{|c|}{$\begin{array}{l}\text { SIRS on admission and odds of poor functional outcomes after ICH in patients who had a pre-ICH mRS } \\
\text { of } 0-2\end{array}$} \\
\hline & & \multicolumn{3}{|c|}{ Discharge mRS 3-6a } & \multicolumn{3}{|c|}{ 3-Mo mRS 3-6a } \\
\hline & & OR & $95 \% \mathrm{Cl}$ & $p$ Value & OR & $95 \% \mathrm{Cl}$ & $p$ Value \\
\hline \multicolumn{2}{|c|}{ No infection or SIRS } & Ref & Ref & Ref & Ref & Ref & Ref \\
\hline \multicolumn{2}{|c|}{ SIRS only } & 1.07 & $0.69-1.67$ & 0.7452 & 1.35 & $0.89-2.04$ & 0.1511 \\
\hline \multicolumn{2}{|c|}{ Infection only } & 3.45 & $2.38-5.00$ & $<0.0001$ & 2.86 & 2.17-3.85 & $<0.0001$ \\
\hline \multicolumn{2}{|c|}{ SIRS and infection } & 4.55 & $2.04-10$ & 0.0002 & 2.38 & $1.39-4.17$ & 0.0016 \\
\hline \multicolumn{8}{|c|}{ Limiting to patients who had a pre-ICH mRS of $0-2$} \\
\hline \multicolumn{2}{|c|}{ No infection or SIRS } & Ref & Ref & Ref & Ref & Ref & Ref \\
\hline \multicolumn{2}{|c|}{ SIRS only } & 1.06 & $0.68-1.67$ & 0.7790 & 1.32 & $0.87-2.00$ & 0.1907 \\
\hline \multicolumn{2}{|c|}{ Infection only } & 3.49 & $2.38-5.00$ & $<0.0001$ & 2.86 & $2.13-3.85$ & $<0.0001$ \\
\hline \multicolumn{2}{|c|}{ SIRS and infection } & 4.35 & $2.00-10.0$ & 0.0002 & 2.33 & $1.33-4.00$ & 0.0027 \\
\hline
\end{tabular}

Abbreviations: $\mathrm{Cl}=$ confidence interval; $\mathrm{ICH}=$ intracerebral hemorrhage; $\mathrm{IVH}=$ intraventricular hemorrhage; $\mathrm{mRS}=$ modified Rankin Scale; OR = odds ratio; SIRS = systemic inflammatory response syndrome; Ref = reference group. ${ }^{a}$ Adjusting for age, IVH, ICH volume, location, and initial GCS.

age, IVH, ICH volume, location, and initial GCS. The associations remained at 3 months after adjusting for age, IVH, hematoma volume and location, and admission GCS (table 3). Restricting to patients who presented with an $\mathrm{ICH}$ score of $0-2$, patients with both SIRS and infections (OR 3.49, 95\% CI 2.38$5.00, p<0.0001)$, as well as patients with only infections (OR 4.35, 95\% CI 2.00-10.0, $p=0.0002$ ), were at increased risk of poor functional outcomes at discharge after adjusting for age, $\mathrm{IVH}$, hematoma volume and location (lobar vs non-lobar), and initial GCS. In this restricted sample, patients with SIRS only were not at increased risk of poor functional outcomes at discharge after ICH (OR 1.06, 95\% CI $0.68-1.67, p=0.7790$ ) after adjusting for age, $\mathrm{IVH}$, hematoma volume and location, and admission GCS. These associations remained at 3 months, but the effect sizes were attenuated after adjusting for age, IVH, hematoma volume and location, and admission GCS (table 3).

DISCUSSION We found in a national, multicenter study among a racially and ethnically diverse population that SIRS was present on admission in $\sim 1$ in 10 patients with ICH and that SIRS on admission was associated with stroke severity and infections during hospitalization, but it was not independently associated with outcomes at discharge and at 3 months after ICH. We found that patients with SIRS and an infection, or an infection only, were at an increased risk of poor functional outcomes at both discharge and 3 months, whereas SIRS in the absence of an infection was not related to outcomes.

Our study found that $14 \%$ of patients with $\mathrm{ICH}$ met SIRS criteria on admission. From this sample, the prevalence of SIRS on admission was lower than that reported for in-hospital SIRS in patients with acute ischemic stroke treated with tissue plasminogen activator (18\%), patients with ICH (23\%), and patients with subarachnoid hemorrhage $(54 \%-86 \%)^{5,6,8}$ The lower prevalence in our population may reflect the fact that SIRS requires time to develop in patients with acute $\mathrm{ICH}$ or the need for a series of assessments over time to make a determination of SIRS.

The relationship between SIRS on admission and in-hospital infection may provide an insight into which patients with ICH are at the highest risk of an infection. The prevalence of infection in this study was consistent with prior research. ${ }^{13}$ Stroke severity, ${ }^{14}$ complications, ${ }^{15}$ and procedures ${ }^{16}$ have been consistently identified as risk factors for poststroke infection. Considering the relationship between SIRS on admission and stroke severity, the relationship between SIRS on admission and infection was not surprising. Furthermore, as shown in patients with trauma, SIRS on admission has been consistently identified as a significant predictor of infection but not outcomes, ${ }^{17}$ whereas persistent SIRS was a significant predictor of both infections and outcomes. ${ }^{18,19}$ These findings suggest that SIRS on admission could be a simple way to identify patients with $\mathrm{ICH}$ at high risk of developing an infection.

Consistent with trauma, our study provides evidence that SIRS on admission is not independently related to functional outcomes at discharge after ICH. In-hospital SIRS, in contrast, was associated with poor functional outcomes at discharge in patients with ICH. ${ }^{8}$ In a single-center study, admission SIRS was a major predictor of in-hospital SIRS, but not independently associated with discharge functional outcomes. However, in-hospital SIRS was associated with poor discharge functional outcomes. ${ }^{8} \mathrm{We}$ 
assessed the relationship between SIRS and infections on long-term outcomes and found that patients who had either SIRS plus an infection or only an infection were at increased risk of poor functional outcomes at discharge and 3 months. SIRS on admission in the absence of an infection was not associated with functional outcomes. Explanation for these discrepancies could be due to differences in the SIRS definition in each study. The strict definition of in-hospital SIRS requires a 24-hour period to meet criteria, so only patients with a sustained inflammatory response are identified as having in-hospital SIRS. Positive association between persistent in-hospital SIRS and poor ICH outcomes are more consistently found in stroke and trauma. ${ }^{8,17,18}$

More severe strokes are associated with the prevalence of SIRS, indicating that SIRS could be due to an inflammatory response from the stroke itself. The exact mechanism, however, is not well understood, with prior research suggesting that inflammation plays a role in the pathophysiology of tissue damage. ${ }^{20-23}$ After accounting for hematoma volume on admission, GCS on admission, and presence of IVH on admission, the relationship between SIRS on admission and outcomes was attenuated. This is consistent with prior work that highlighted a relationship between SIRS on admission and markers of stroke severity, but not an independent association with stroke outcomes. ${ }^{24}$

This study identified a strong relationship between SIRS on admission and stroke severity, as defined as ICH score. This finding supports previous research in acute ischemic stroke, $\mathrm{ICH}$, and subarachnoid hemorrhage, where there were strong positive associations between stroke severity and identification of SIRS during hospitalization. ${ }^{25}$ These findings suggest that inflammation might be one mechanism by which stroke severity influences stroke outcomes. This was expected considering that individual components of SIRS criteria and stroke severity, hematoma growth, and hemorrhage volume have been linked in prior research. ${ }^{26-30}$

Identifying patients at increased risk of poor outcomes and subsequently treating the patient or reducing the risk of poor outcomes is of great clinical importance. However, there are no specific treatments for SIRS. Use of anti-inflammatory or immunosuppressive treatments for SIRS, or any type of poststroke inflammatory response, is complicated by the potential for an increased risk of infection with immunosuppression. ${ }^{31}$ In patients with both ischemic and hemorrhagic stroke, potential treatment options for poststroke inflammation include stem cells (by protecting neurons from immune cell-mediated apoptosis), therapeutic hypothermia, inhibition of microglial activation, minocycline, natalizumab, and fingolimod. ${ }^{32-37}$ Treating poststroke inflammation is further complicated by the beneficial role of the immune response after stroke, as the immune response can aid in stroke recovery. ${ }^{37}$ The utility of the immune response after stroke is believed to explain why identification of a consistent treatment for inflammation after stroke has not been identified.

This study has a number of limitations. The ERICH study was intended to assess the genetic risk factors for ICH. This analysis was not a prespecified aim of the ERICH study; thus, only baseline measures of vital signs are available, preventing the investigation of later development of SIRS during hospitalization. Testing for infection was performed only if clinical indications existed; thus, potential bias may exist for infection diagnosis. However, this bias is nondifferential and subsequently would bias our results toward the null. Furthermore, we did not have information on inflammatory biomarkers, such as C-reactive protein (CRP), at any time point. Further studies are needed to investigate the prognostic role of inflammatory biomarkers, such as CRP, in identifying inflammatory responses after an ICH. It is possible that CRP is a more sensitive and specific biomarker of inflammation than SIRS and could be a better indicator of the underlying infection. ${ }^{38-40}$ The advantage to a measure such as SIRS, however, is that it is widely available at no extra cost. ERICH was also designed to enroll an equal number of whites, blacks, and Hispanics, and as such, is not representative of the whole population. The inhospital mortality rate is lower in the ERICH report $(7.9 \%)$ than in prior reports, and the 90-day case fatality rate in this sample is $21.5 \%$. The reduced case fatality rates at discharge and 90 days could influence the generalizability to only patients with $\mathrm{ICH}$ with milder strokes. Our study also has significant strengths, including a large, diverse population enrolled at a number of centers with experience in caring for patients with ICH. In addition, we were able to use a wealth of data on participants using information collected as part of the standard of care for patients with ICH.

SIRS on admission was identified in $14 \%$ of patients with $\mathrm{ICH}$ and was associated with stroke severity, infections, and outcomes. Accounting for stroke severity and other risk factors, SIRS on admission remained an independent risk factor for infectious complications in patients with ICH. After accounting for stroke severity and infections, SIRS on admission was no longer independently related to functional outcomes at discharge or 3 months.

\section{AUTHOR CONTRIBUTIONS}

Amelia K. Boehme: study concept and interpretation of data. Mary E. Comeau and Carl D. Langefeld: data analysis and interpretation. Aaron Lord: critical revision of the manuscript. Charles J. Moomaw and 
Jennifer Osborne: acquisition of data and interpretation of data. Michael L. James, Sharyl Martini, and Fernando D. Testai: critical revision of the manuscript. Daniel Woo: study design, acquisition of data, and critical revision of the manuscript. Mitchell S.V. Elkind: critical revision of the manuscript.

\section{STUDY FUNDING}

This study was supported by a grant from the National Institute of Neurological Disorders and Stroke (NINDS: U-01-NS069763).

\section{DISCLOSURE}

A. Boehme reports no disclosures. M.E. Comeau reports no disclosures. C.D. Langefeld served on the scientific advisory board of the Oklahoma Medical Research Foundation and Wake Forest Nonhuman Primate Center; received travel funding and/or speaker honoraria from NIH; served on the editorial board of Rheumatic Disease Clinics; and received research support from the NINDS, NIH, NCI Comprehensive Cancer Center of Wake Forest University, NIDDK, NHLBI, NCI Wake Forest NCORP Research Base, and the RILITE Foundation. A. Lord reports no disclosures. C. Moomaw received research support from NIND. J. Osborne received research support from NIH-NS. M.L. James reports no disclosures. S. Martini received research support from the NIH/NINDS. F.D. Testai received research support from the NIHJ and was an expert witness in a legal case. D. Woo served as an associate editor of Stroke Research and Treatment and received research support from NIH. M.S.V. Elkind served on the scientific advisory board of Boehringer Ingelheim Inc, BMS-Pfizer, Biotelemetry, CardioNet, and Sanofi-Regeneron; served as Resident and Fellow Section Editor of Neurology; is a section editor of Stroke; received publishing royalties from UpToDate; consulted for Abbott; serves on the board of directors for the American Heart Association; received research support from NIH/NINDS; and participated in legal proceedings for Organon/Merck, BMS-Sanofi, Hi-Tech, DMAA and Stroke, and Auxilium. Go to Neurology.org/nn for full disclosure forms.

Received August 9, 2017. Accepted in final form November 6, 2017.

\section{REFERENCES}

1. Jauch EC, Saver JL, Adams HP Jr, et al. Guidelines for the early management of patients with acute ischemic stroke: A guideline for healthcare professionals from the American Heart Association/American Stroke Association. Stroke 2013;44:870-947.

2. Lord AS, Langefeld CD, Sekar P, et al. Infection after intracerebral hemorrhage: Risk factors and association with outcomes in the ethnic/racial variations of intracerebral hemorrhage study. Stroke 2014;45:3535-3542.

3. Bone RC, Balk RA, Cerra FB, et al. Definitions for sepsis and organ failure and guidelines for the use of innovative therapies in sepsis. The ACCP/SCCM Consensus Conference Committee. American College of Chest Physicians/Society of Critical Care Medicine. Chest 1992;101:16441655.

4. van Diepen S, Vavalle JP, Newby LK, et al. The systemic inflammatory response syndrome in patients with stsegment elevation myocardial infarction. Crit Care Med 2013;41:2080-2087.

5. Chang TR, Boehme AK, Aysenne A, et al. Nadir hemoglobin is associated with poor outcome from intracerebral hemorrhage. Springerplus 2013;2:379.

6. Yoshimoto Y, Tanaka Y, Hoya K. Acute systemic inflammatory response syndrome in subarachnoid hemorrhage. Stroke 2001;32:1989-1993.

7. Reith J, Jorgensen HS, Pedersen PM, et al. Body temperature in acute stroke: Relation to stroke severity, infarct size, mortality, and outcome. Lancet 1996;347:422-425.
8. Boehme AK, Hays AN, Kicielinski KP, et al. Systemic inflammatory response syndrome and outcomes in intracerebral hemorrhage. Neurocrit Care 2016;25:133-140.

9. Hemphill JC III, Bonovich DC, Besmertis L, Manley GT, Johnston SC. The ICH score: A simple, reliable grading scale for intracerebral hemorrhage. Stroke 2001;32: 891-897.

10. Boehme AK, Kapoor N, Albright KC, et al. Systemic inflammatory response syndrome in tissue-type plasminogen activator-treated patients is associated with worse short-term functional outcome. Stroke 2013;44:23212323.

11. Savitz SI, Lew R, Bluhmki E, Hacke W, Fisher M. Shift analysis versus dichotomization of the modified rankin scale outcome scores in the NINDS and ECASS-II trials. Stroke 2007;38:3205-3212.

12. Bender R, Lange $S$. Adjusting for multiple testing-when and how? J Clin Epidemiol 2001;54:343-349.

13. Westendorp WF, Nederkoorn PJ, Vermeij JD, Dijkgraaf MG, van de Beek D. Post-stroke infection: A systematic review and meta-analysis. BMC Neurol 2011;11:110.

14. Diedler J, Sykora M, Hahn P, et al. C-reactive-protein levels associated with infection predict short- and longterm outcome after supratentorial intracerebral hemorrhage. Cerebrovasc Dis 2009;27:272-279.

15. Ali M, Lyden P, Sacco RL, Shuaib A, Lees KR; Investigators $\mathrm{V}$. Natural history of complications after intracerebral haemorrhage. Eur J Neurol 2009;16:624-630.

16. Sykora M, Diedler J, Poli S, et al. Autonomic shift and increased susceptibility to infections after acute intracerebral hemorrhage. Stroke 2011;42:1218-1223.

17. Bochicchio GV, Napolitano LM, Joshi M, McCarter RJ $\mathrm{Jr}$, Scalea TM. Systemic inflammatory response syndrome score at admission independently predicts infection in blunt trauma patients. J Trauma 2001;50:817-820.

18. Bochicchio GV, Napolitano LM, Joshi M, et al. Persistent systemic inflammatory response syndrome is predictive of nosocomial infection in trauma. J Trauma 2002;53:245250; discussion 250-251.

19. Hoover L, Bochicchio GV, Napolitano LM, et al. Systemic inflammatory response syndrome and nosocomial infection in trauma. J Trauma 2006;61:310-316; discussion 316-317.

20. Danton GH, Dietrich WD. Inflammatory mechanisms after ischemia and stroke. J Neuropathol Exp Neurol 2003;62:127-136.

21. Lindsberg PJ, Grau AJ. Inflammation and infections as risk factors for ischemic stroke. Stroke 2003;34:25182532.

22. D'Ambrosio AL, Pinsky DJ, Connolly ES. The role of the complement cascade in ischemia/reperfusion injury: Implications for neuroprotection. Mol Med 2001;7:367-382.

23. Pedersen ED, Waje-Andreassen U, Vedeler CA, Aamodt G, Mollnes TE. Systemic complement activation following human acute ischaemic stroke. Clin Exp Immunol 2004; 137:117-122.

24. Kalita J, Bastia J, Bhoi SK, Misra UK. Systemic inflammatory response syndrome predicts severity of stroke and outcome. J Stroke Cerebrovasc Dis 2015;24:1640-1648.

25. Audebert HJ, Rott MM, Eck T, Haberl RL. Systemic inflammatory response depends on initial stroke severity but is attenuated by successful thrombolysis. Stroke 2004; $35: 2128-2133$ 
26. Power C, Henry S, Del Bigio MR, et al. Intracerebral hemorrhage induces macrophage activation and matrix metalloproteinases. Ann Neurol 2003;53:731-742.

27. Felberg RA, Grotta JC, Shirzadi AL, et al. Cell death in experimental intracerebral hemorrhage: the "black hole" model of hemorrhagic damage. Ann Neurol 2002;51: 517-524.

28. Agnihotri S, Czap A, Staff I, Fortunato G, McCullough LD. Peripheral leukocyte counts and outcomes after intracerebral hemorrhage. J Neuroinflammation 2011;8:160.

29. Leira R, Davalos A, Silva Y, et al. Early neurologic deterioration in intracerebral hemorrhage: predictors and associated factors. Neurology 2004;63:461-467.

30. Zhao X, Zhang Y, Strong R, Grotta JC, Aronowski J. 15dprostaglandin $\mathrm{j} 2$ activates peroxisome proliferator-activated receptor-gamma, promotes expression of catalase, and reduces inflammation, behavioral dysfunction, and neuronal loss after intracerebral hemorrhage in rats. J Cereb Blood Flow Metab 2006;26:811-820.

31. Santos Samary C, Pelosi P, Leme Silva P, Rieken Macedo Rocco P. Immunomodulation after ischemic stroke: potential mechanisms and implications for therapy. Crit Care 2016;20:391.

32. Elkins J, Veltkamp R, Montaner J, et al. Safety and efficacy of natalizumab in patients with acute ischaemic stroke (action): a randomised, placebo-controlled, double-blind phase 2 trial. Lancet Neurol 2017;16:217-226.
33. Kim JY, Kawabori M, Yenari MA. Innate inflammatory responses in stroke: mechanisms and potential therapeutic targets. Curr Med Chem 2014;21:2076-2097.

34. Broughton BR, Lim R, Arumugam TV, Drummond GR, Wallace EM, Sobey CG. Post-stroke inflammation and the potential efficacy of novel stem cell therapies: focus on amnion epithelial cells. Front Cell Neurosci 2012;6:66.

35. Wang J, Tsirka SE. Tuftsin fragment 1-3 is beneficial when delivered after the induction of intracerebral hemorrhage. Stroke 2005;36:613-618.

36. Zhou Y, Wang Y, Wang J, Anne Stetler R, Yang QW. Inflammation in intracerebral hemorrhage: from mechanisms to clinical translation. Prog Neurobiol 2014;115:25-44.

37. Zheng $\mathrm{H}$, Chen $\mathrm{C}$, Zhang J, Hu Z. Mechanism and therapy of brain edema after intracerebral hemorrhage. Cerebrovasc Dis 2016;42:155-169.

38. Lopponen P, Qian C, Tetri S, et al. Predictive value of creactive protein for the outcome after primary intracerebral hemorrhage. J Neurosurg 2014;121:1374-1379.

39. Juvela S, Kuhmonen J, Siironen J. C-reactive protein as predictor for poor outcome after aneurysmal subarachnoid haemorrhage. Acta Neurochir (Wien) 2012;154:397-404.

40. Turner CL, Budohoski K, Smith C, et al. Elevated baseline c-reactive protein as a predictor of outcome after aneurysmal subarachnoid hemorrhage: data from the simvastatin in aneurysmal subarachnoid hemorrhage (STASH) trial. Neurosurgery 2015;77:786-792; discussion 792-793. 


\section{Neurology \\ Neuroimmunology \& Neuroinflammation}

\section{Systemic inflammatory response syndrome, infection, and outcome in intracerebral hemorrhage}

Amelia K. Boehme, Mary E. Comeau, Carl D. Langefeld, et al.

Neurol Neuroimmunol Neuroinflamm 2018;5;

DOI 10.1212/NXI.0000000000000428

This information is current as of December 26, 2017

\section{Updated Information \& \\ Services}

Supplementary Material

References

Subspecialty Collections

Permissions \& Licensing

Reprints including high resolution figures, can be found at:

http://nn.neurology.org/content/5/2/e428.full.html

Supplementary material can be found at:

http://nn.neurology.org/content/suppl/2017/12/26/5.2.e428.DC1

This article cites 40 articles, 10 of which you can access for free at: http://nn.neurology.org/content/5/2/e428.full.html\#\#ref-list-1

This article, along with others on similar topics, appears in the following collection(s):

All epidemiology

http://nn.neurology.org//cgi/collection/all_epidemiology

All Infections

http://nn.neurology.org//cgi/collection/all_infections

Intracerebral hemorrhage

http://nn.neurology.org//cgi/collection/intracerebral_hemorrhage

Information about reproducing this article in parts (figures,tables) or in its entirety can be found online at:

http://nn.neurology.org/misc/about.xhtml\#permissions

Information about ordering reprints can be found online:

http://nn.neurology.org/misc/addir.xhtml\#reprintsus

Neurol Neuroimmunol Neuroinflamm is an official journal of the American Academy of Neurology.

Published since April 2014, it is an open-access, online-only, continuous publication journal. Copyright

Copyright $\odot 2017$ The Author(s). Published by Wolters Kluwer Health, Inc. on behalf of the American

Academy of Neurology.. All rights reserved. Online ISSN: 2332-7812.

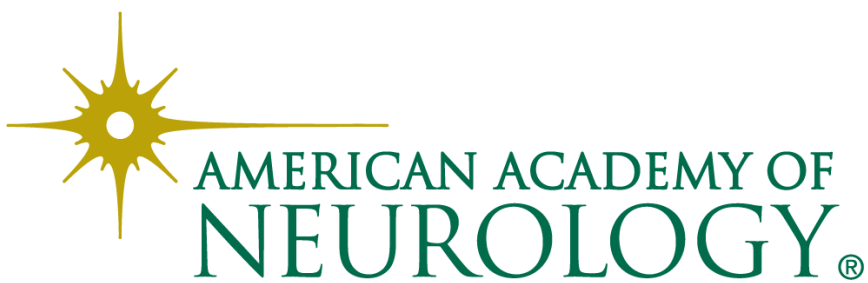

